\title{
Tropical cyclone formation in the North Atlantic Basin, 1960-1989
}

\author{
Anthony J. Vega ${ }^{1}$, Mark S. Binkley ${ }^{2}$ \\ ' Louisiana State University, Baton Rouge, Louisiana, USA \\ ${ }^{2}$ Mississippi State University, Mississippi State, Mississippi, USA
}

\begin{abstract}
All tropical cyclones originating in the North Atlantic Basin from 1960 through 1989 that made landfall along the United States coast were analyzed. The storms were divided into categories based on formation area ( 6 independent regions) and analyzed according to their paths to landfall (along the Gulf and Atlantic coasts), time of year of formation (month of the hurricane season), and highest intensity attained (using the Saffir-Simpson Scale). For each formation region, tropical cyclone patterns were identified and climatological explanations of fered. Cyclones developing early and late in the hurricane season were weak in intensity, developed mainly in the Gulf of Mexico and affected the Gulf Coast states. The formation areas shifted eastward in mid-hurricane season, first developing in the Caribbean and then in the 'Cape Verde' region. A return to the west was apparent late in the season, with maximum development in the Atlantic region and finally in the Gulf late in the season. Intensities tended to increase with formation distance from the U.S. coast. The role of the Bermuda-Azores High was found to be critical with regard to tropical cyclogenesis and cyclone paths from each formation region.
\end{abstract}

\section{INTRODUCTION}

The tropical cyclone constitutes one of the most destructive natural disasters, affecting many countries around the globe and exacting tremendous annual losses in lives and property (Jarrell 1985). The approximately 80 tropical cyclones that occur around the globe each year cause an average $\$ 10$ billion (in 1979 U.S. dollars) in damage and 10000 deaths (Southern 1979). Over the North Atlantic, an average of 100 tropical disturbances occur each year. While most of these will not have sufficient organization to cause great damage, a few will develop into hurricanes. During the period 1960 to 1989 , there were 280 tropical storms and hurricanes which originated in the North Atlantic Basin. Of these, 76 made landfall on the continental United States. Therefore, approximately 3 tropical cyclones on average will make landfall in the contiguous U.S. each year.

It has been determined that the amount of property damage from tropical cyclones is directly associated with increased development at coastal locations, with most of the damage occurring within $91 \mathrm{~m}(300 \mathrm{ft})$ of the high tide mark ( $N$. Frank pers. comm.). Development within this area has been increasing at a dramatic rate within the last $30 \mathrm{yr}$. The loss of life associated with tropical cyclones, fortunately, has decreased dramatically in developed countries with the advent of advanced warning procedures.

With tropical cyclones resulting in billions of dollars of destruction and numerous deaths each year, their continuous study is warranted. This study will help determine where tropical storms and hurricanes that affect the U.S. are most likely to form, as well as identify their average intensity, paths of travel, time of year and resultant landfall location. A methodology which incorporates all tropical cyclones becomes mired in magnitude (Lawrence 1989). This study, therefore, incorporates only those tropical cyclones which made landfall, allowing for a more complete understanding of the processes involved in guiding these storms onto the U.S. coast. A better understanding of tropical 
cyclone climatology may be gained through this study and, as a result, better preparation against these destructive storms may be possible, thus reducing the number of deaths and the amount of property damage.

\section{TROPICAL CYCLONE BACKGROUND}

\section{Genesis}

Extratropical. Hurricanes can take many different forms, due primarily to the location of their formation. Cold-core hurricanes (which are rare) may occur poleward of $30^{\circ}$ latitude, thus creating a sub-tropical cyclone. Sub-tropical cyclones are defined as nonfrontal low pressure systems comprising initial coldcore (baroclinic) circulations which develop over sub-tropical waters (Hebert \& Poteat 1975). This can occur when cold lows cut off near $200 \mathrm{mb}$ and when upper air troughs extend from the mid-latitudes into the tropics. Chaston (1988) found that about $14 \%$ of all cut-off lows develop near Cape Hatteras, North Carolina, and can persist for up to $2 \mathrm{wk}$. Also, remnants of a polar front can induce convection and occasionally generate a sub-tropical cyclone, especially when sufficient upper-air venting is evident (Lewis \& Hsu 1992).

Shapiro (1989) found a correlation between the 'nor'easter' and hurricane development. A 'nor'easter' is a storm which develops in the Atlantic Ocean from an area of low pressure, usually in association with a cold front, which rejuvenates as the storm passes into an area of extreme baroclinicity (warm ocean water). The resulting winds and wrap-around moisture strike the continent from the northeast, hence the name. Shapiro has indicated that the 'nor'easter' may actually be an extratropical hurricane which develops in these latitudes during the cool season.

Extratropical cyclones may also occur when a tropical cyclone migrates into a non-tropical environment and undergoes modification. The size of the cyclone typically expands, causing a reduction in wind speed and a redistribution of winds, rainfall and temperature around a center which becomes increasingly asymmetric (Allen 1976).

Tropical. This study is concerned only with true tropical cyclones. These cyclones have been found to pass through 3 or 4 stages of development: (1) intensification, (2) maturity, (3) decay, or occasionally (4) modification. These cyclones typically develop from tropical waves which move off the coast of Africa near 10 to $15^{\circ} \mathrm{N}$ (Neumann et al. 1987). Gray (1968) found that about $80 \%$ of all tropical cyclones form either in, or slightly poleward of the Inter-Tropical Convergence Zone (ITCZ). The ITCZ is defined as the region of low level convergence and convection located equatorward of the primary trade-wind flow (Frank 1985). This zone of convergence is normally located in the Northern Hemisphere and is displaced farthest poleward at the height of the hurricane season. Therefore, $87 \%$ of all tropical cyclones which originate in the North Atlantic develop within $20^{\circ} \mathrm{N}$ of the equator (Frank 1985).

Many tropical cyclones develop directly from easterly waves which move off the coast of Africa in the primary trade-wind flow. An easterly wave is an inverted trough (axis directed poleward) which moves generally westward in the easterly trades with the low level convergence and associated convective weather along the eastern side of the axis. Most of these waves begin as an area of instability in the easterly flow near $10^{\circ} \mathrm{N}$ in east or central Africa (Gray 1990). Approximately 64 easterly waves occur in the North Atlantic Basin each year (Chaston 1988).

Tropical cyclones typically intensify in this convective region only when water temperatures are above $26^{\circ} \mathrm{C}\left(79^{\circ} \mathrm{F}\right)$. Here, the amount of latent heat of vaporization is sufficient to maintain and intensify the developing surface low pressure system. As the wave moves into higher latitudes (usually poleward of $15^{\circ}$ ), cyclonic circulation about the low may begin as the result of increasing Coriolis deflection (Hsu 1988). The easterly wave can then progress through the 4 stages to become a hurricane (Table 1).

Hurricanes are thought to be a major factor in the maintenance of the atmospheric heat and moisture balance between the tropics and extra-tropical latitudes. Landsberg (1960) suggests that hurricanes may provide a kind of 'safety-valve' that limits the continued build-up of heat and energy in the tropical latitudes.

\section{Seasonal shifts of tropical cyclone formation}

Tropical cyclone tracks vary in different ocean basins with respect to cyclone size, intensity and frequency (Frank 1985). The annual number of tropical

Table 1. The 5 stages of tropical cyclone intensification

\begin{tabular}{|lccc|}
\hline Stage & $\begin{array}{c}\text { Winds } \\
\left(\mathrm{km} \mathrm{h}^{-1}\right)\end{array}$ & $\begin{array}{c}\text { Pressure } \\
(\mathrm{mb})\end{array}$ & Isobars \\
\hline Easterly wave & - & - & Ridging \\
Tropical disturbance & - & - & Organizing \\
Tropical depression & $\leq 61$ & - & Closing \\
Tropical storm & $62-117$ & $\geq 981$ & 1 Closed \\
Hurricane & $\geq 118$ & $\leq 980$ & $>1$ Closed \\
\hline
\end{tabular}


cyclones which originate within the North Atlantic Basin over the last century is highly variable, with totals ranging from 1 to 21 storms. No long-term trends have been identified concerning storm frequencies in this basin, due to the brevity of the climatic record. However, seasonal shifts in the principal areas of tropical cyclone formation over the North Atlantic Ocean have been recognized for many decades (Crutcher \& Quayle 1974).

The seasonal shifts of tropical cyclone formation areas result from the migration of the vertical rays of the sun during the hurricane season and the corresponding high water temperatures. The official North Atlantic hurricane season extends from 1 June through 30 November, but the storm season usually does not become highly active until early August and typically diminishes by the end of October (Frank 1985). However, tropical cyclones have been reported as early as May and as late as December.

Early season cyclones (those forming in June) have been observed to occur almost exclusively in the Western Caribbean and the Gulf of Mexico (Neumann et al. 1987) with the associated tracks primarily to the north (Elsberry 1985). Near the end of June, the genesis area shifts eastward accompanied by a slight decline in the overall frequency of storms. By late July, the frequency increases as the genesis area shifts farther eastward (north of the West Indies). By late August the formation area has shifted to its farthest eastern location, near the Cape Verde Islands. Storm frequencies reach a maximum during this time, with most storms traversing the entire Atlantic after initial formation. After mid-September, the formation area shifts westward with a corresponding decline in frequency. By early October, the formation area is generally confined to longitudes west of $60^{\circ} \mathrm{W}$, and the area of maximum occurrence is once again the Western Caribbean. During November, the formation area retreats into the Western Caribbean and the Gulf of Mexico, accompanied by the largest decline in cyclone frequency (Table 2).

Table 2. Hurricane formation regions by time of year

\begin{tabular}{|ll|}
\hline Season & Area of genesis \\
\hline June & $\begin{array}{l}\text { Gulf of Mexico and } \\
\text { Western Caribbean }\end{array}$ \\
July-August & North of West Indies \\
August-September & Cape Verde Islands \\
September-October & West of $60^{\circ}$ W \\
October-November & Gulf of Mexico and \\
& Western Caribbean \\
\hline
\end{tabular}

\section{Tropical cyclone movement}

Typical movement of North Atlantic tropical cyclones is toward the north-northwest at about 16 to $32 \mathrm{~km} \mathrm{~h}^{-1}$ (10 to $20 \mathrm{mph}$ ). The Bermuda-Azores high pressure system typically aids in the steering of the cyclones westward in the southeasterly trade-wind flow. As the cyclones move into more northerly latitudes in lee of the high, they generally curve toward the north-northeast. This is due primarily to the storms being affected by the mean westerly wind flow as well as Coriolis deflection which curves the storm toward the northeast (Hsu 1988). Due to the presence of the high and the distribution of land and sea, tropical cyclones in the North Atlantic generally form at higher latitudes and recurve at higher latitudes than in other ocean basins (Elsberry 1985)

One basic feature of tropical cyclone motion is the difference in the characteristics before and after recurvature. The meridional component generally increases in magnitude as the storms move into the midlatitudes. Cyclones in the easterlies have a much smaller $24 \mathrm{~h}$ displacement than in the westerlies and also have a much smaller standard deviation about the mean (Elsberry 1985).

Vallee (1990) noted a tendency for tropical cyclones to recurve northward sooner and with more frequency during ENSO (El Niño/Southern Oscillation) events, although the forcing mechanisms are not completely understood. In addition, synoptic scale conditions, such as migratory high and low pressure systems, may affect the paths of tropical cyclones. Eagleman (1983) suggests that large variations in the tracks of some tropical cyclones are caused by the influence of synoptic scale systems in the mid-latitudes. Due to these and other factors, large forecast errors are usually made after the cyclones have recurved into higher latitudes.

\section{METHODOLOGY}

Data sources. This study includes all tropical storms and hurricanes which formed during the years 1960 to 1989 inclusive. Observed data were taken from 'Tropical Cyclones of the North Atlantic Ocean, 1871-1986' (Neumann et al. 1987) as well as the 1988-1990 February issues of 'Weatherwise' (Case 1988, 1990, Lawrence 1989). The highest intensity a storm reached on the Saffir-Simpson Hurricane Intensity Scale (Simpson \& Riehl 1981) was used for that storm throughout the analysis. The first area in which the cyclone eye passed onto land in the United States was used as the storm's point of landfall. Multiple landfall strikes by the same storm were not analyzed. The date on which the refer- 
ence materials (hence the National Hurricane Center) first recorded the storm track was used as the date of storm formation and that point was used as the cyclogenesis area.

Formation. Six regions of tropical cyclone formation were identified and used. Initial formation areas were based upon recognized formation areas as identified by Neumann et al. (1987), Chaston (1988) and Reading (1989). However, the formation areas were further expanded, redefined and given set boundaries by using 'best track' analysis. For example, cyclones appeared to move to the north after formation in the Western Gulf of Mexico but the movement of storms which formed in the Eastern Gulf was either toward the northeast or northwest. Therefore, the Gulf of Mexico was broken into 2 independent formation zones, west and east.

The 6 formation areas defined by this study are: (1) Western Gulf of Mexico; (2) Eastern Gulf of Mexico; (3) Southwest Atlantic (4) Caribbean; (5) Cape Verde; and (6) Atlantic (Fig. 1).

The Western Gulf of Mexico formation area is defined as the area west of $90^{\circ} \mathrm{W}$ to the U.S. and Mexican coast. The Eastern Gulf of Mexico is defined as the area east of $90^{\circ} \mathrm{W}$ to the southern tip of Florida and southward to the western tip of Cuba, and extending to the eastern shore of the Yucatan Peninsula. The Southwest Atlantic formation region is defined as the area extending eastward from the southern tip of Florida and the northern shore of Cuba to $70^{\circ} \mathrm{W}$ and from $20^{\circ} \mathrm{N}$ to $30^{\circ} \mathrm{N}$. The Caribbean formation zone is defined as the region extending from the northern shore of Cuba and the Yucatan Peninsula southward to South America, and eastward to the Lesser Antilles. The Cape Verde region is defined as the area extending eastward from the Lesser Antilles to the coast of Africa, from $20^{\circ} \mathrm{N}$ to the equator. Finally, the Atlantic formation region is defined as the area poleward of $20^{\circ} \mathrm{N}$ from $70^{\circ} \mathrm{W}$ to the coast of Africa and Europe.

\section{CYCLOGENESIS OVERVIEW}

Before examining the 6 formation zones in detail, it is first prudent to examine the percentage of storms from each formation area which made landfall in the U.S. throughout the study period (Fig. 2). A total of 22 tropical cyclones formed in the Western Gulf of Mexico formation region. Of these, 13 (59\%) made direct landfall in the U.S. Of the 17 tropical cyclones which originated in the Eastern Gulf formation region, 10 (59\%) made landfall in the U.S. Due to the proximity of these

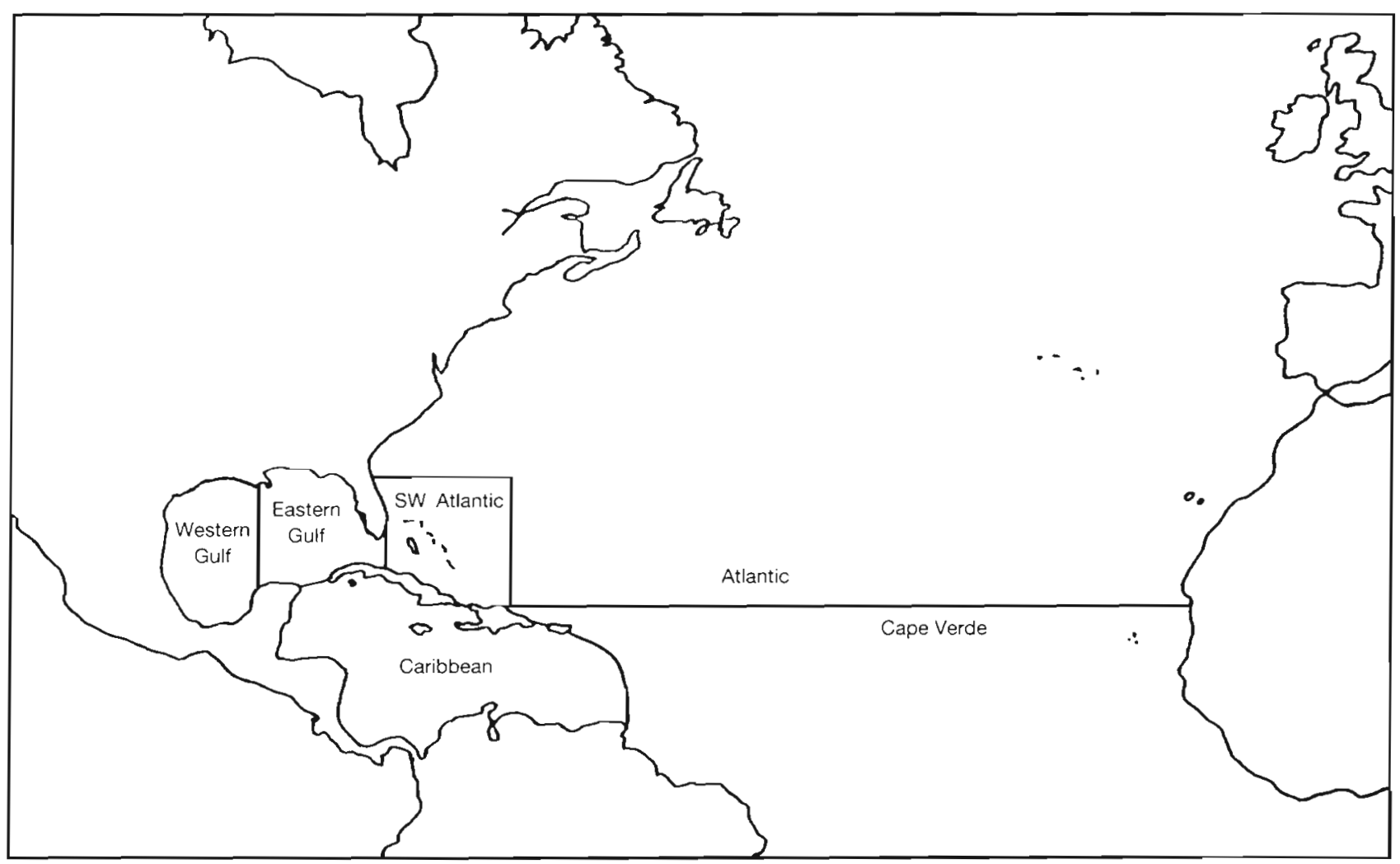

Fig. 1. North Atlantic Basin tropical cyclone formation regions 


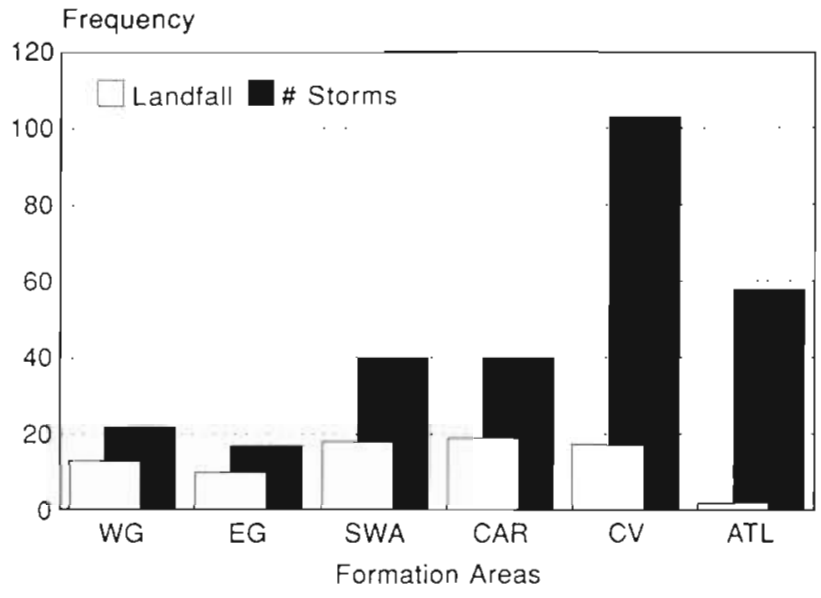

Fig. 2. Total number of tropical cyclones formed compared to those which made landfall in the U.S. per formation region: $W G=$ Western Gulf of Mexico; $E G=$ Eastern Gulf of Mexico; SWA $=$ Southwest Atlantic $;$ CAR $=$ Caribbean $; C V=$ Cape Verde; $A T L=$ Atlantic

2 formation regions to the U.S. coast, it is not surprising that the highest landfall percentage of all the formation zones occurred in relation to these 2 formation regions. Furthermore, these formation regions were the most stable throughout the study period, as cyclogenesis was well distributed through the hurricane season. Lewis \& Hsu (1992) credit this phenomenon to the persistence of the Loop Current in the central Gulf of Mexico and resulting spin-off warm-water eddies. These warm-water pools have been linked to both tropical cyclone activity as well as cool season meteorological bombs (Lewis \& Hsu 1992).

As expected, storms which originated within the Southwest Atlantic formation area had a lower percentage of landfall (18 of the 40 storms, or $45 \%$ ) as compared with the 2 Gulf of Mexico regions. This lower percentage is probably due to the proximity of the Subtropical High Pressure System (STH), which allows cyclogenesis to occur in its lee when weak or displaced eastward, but also aids in the rapid recurvature of the storms away from the U.S. mainland. When the STH is displaced westward, cyclogenesis would ultimately be retarded due to subsidence in the formation region.

The Caribbean formation region produced a total of 40 tropical cyclones as well, of which 19 (48\%) made landfall in the U.S. The low latitude of the formation region and the strong easterly flow of the trade-winds help steer many of the cyclones into portions of Central America, where dissipation occurs. The strength and position of the STH are again integral to the cyclone track as this system generates the constant easterly trade-wind flow. Therefore, at times when the STH is anomalously strong or displaced westward, cyclones which originate within this area typically drift farther westward than normal.

A total of 103 tropical cyclones originated in the Cape Verde formation area during the study period, constituting by far the largest number of storms from any of the formation regions. Of these, only $17 \mathrm{cy}$ clones made landfall in the U.S. (a very low landfall percentage of $16.5 \%$ ). The large majority of these storms either drifted into Central America or recurved before making landfall in the U.S., subsequently dissipating over open waters.

Again, the strength and position of the STH seem to be the critical factors in the ultimate cyclone track. Walsh (1977) has suggested that the recent lower frequency of Cape Verde storms which affect the eastern seaboard of the U.S. is related to the equatorward displacement of the average storm track. Spencer \& Douglas (1985) state that tropical cyclones have undergone a shift recently in which recurvature occurs much later in the average track than was seen earlier in the climatic record. Furthermore, Gray (1990) noted a relationship between hurricane frequency (especially in Cape Verde storms) and rainfall in the Sahel region of Africa. Vega (1993) suggests that all three of these observations are linked to variations in the Hadley circulation and the resulting strength and position of both the STH and the ITCZ.

When the ITCZ is displaced equatorward, the Sahel undergoes drought conditions while the STH expands in response to the lower latitude of the ITCZ. However, it is not known whether the expansion of the STH is the result or cause of ITCZ displacement. It is thought that these conditions combine to create drought conditions in the Sahel region (through greater subsidence associated with the STH as well as the lack of a precipitation generating mechanism, the ITCZ), a displacement of cyclone tracks equatorward (through steering induced by the displaced STH), and later-than-normal recurvature (also from the displaced STH which will cause the cyclones to drift farther westward in the strong easterly trade-wind flow). Therefore, the STH is a critical determinant of the resulting cyclone tracks and variations in this pressure system may account for the low landfall percentage (in the U.S.) with regard to Cape Verde storms.

The Atlantic formation zone is perhaps the most interesting in that the region produced the second greatest number of storms (58) but only 2 of these made landfall in the U.S. This results in the lowest landfall percentage for any of the formation regions $(3.4 \%)$. The reason for this phenomenon is not readily apparent. Cyclogenesis occurs with regularity in this region but perhaps the latitude of the region aids in early recurvature, ultimately resulting in very few threatening (in terms of the U.S. coastline) cyclones. 


\section{ANALYSIS}

One-way analysis of variance was used to examine whether one formation region produced significantly more intense storms than any other. All storms which made landfall within the study period were placed into groups according to their respective formation regions and individual storm wind speeds. Because of the wide spread of scores, the Welch-Aspin procedure was used to provide for better homogeneity of variance. This procedure computes and uses the square root of the scores, thereby reducing the overall variance and providing homogeneity.

The groups were then compared and a probability value of 0.002 was found, indicating that a significant difference in the mean wind speeds exist between formation regions. A Scheffe contrast test (Dowdy \& Wearden 1991) was used to determine which formation region produced the significantly higher winds as compared to all other regions. The analysis indicated that the Cape Verde formation region produced, on average, the more intense storms. This is probably related to the average period of time the storms remained over warm ocean waters before making landfall in the U.S., which ensured the maximum growth of each storm before landfall was achieved.

\section{Gulf of Mexico}

Tropical cyclones produced in the Western Gulf formation region were characterized by storm tracks which were primarily due north (Fig. 3). Persistence is evident as very few storms deviated from this track, with recurvature only after landfall was made. Furthermore, the formation region was characterized mainly by low intensity cyclones (Table 3 ).

Table 3. Frequency of tropical cyclone intensity from formation zones. Intensities are derived from the Saffir-Simpson Hurricane Intensity Scale (Simpson \& Riehl 1981) and are shown here arranged from lowest intensity (tropical storm, T.S.) to higher intensity (Category 5, Cat. 5). WG = Western Gulf; $\mathrm{EG}=$ Eastern Gulf; SWA = Southwest Atlantic $; \mathrm{CAR}=$ Caribbean $\mathrm{CV}=$ Cape Verde $; \mathrm{ATL}=$ Atlantic

\begin{tabular}{|lcccccc|}
\hline & T.S. & Cat. 1 & Cat. 2 & Cat. 3 & Cat. 4 & Cat. 5 \\
\hline WG & 5 & 6 & 0 & 1 & 0 & 1 \\
EG & 6 & 4 & 0 & 0 & 0 & 0 \\
SWA & 7 & 5 & 2 & 1 & 1 & 0 \\
CAR & 5 & 6 & 1 & 4 & 1 & 1 \\
CV & 3 & 1 & 0 & 2 & 5 & 6 \\
ATL & 1 & 0 & 0 & 1 & 0 & 0 \\
\hline
\end{tabular}

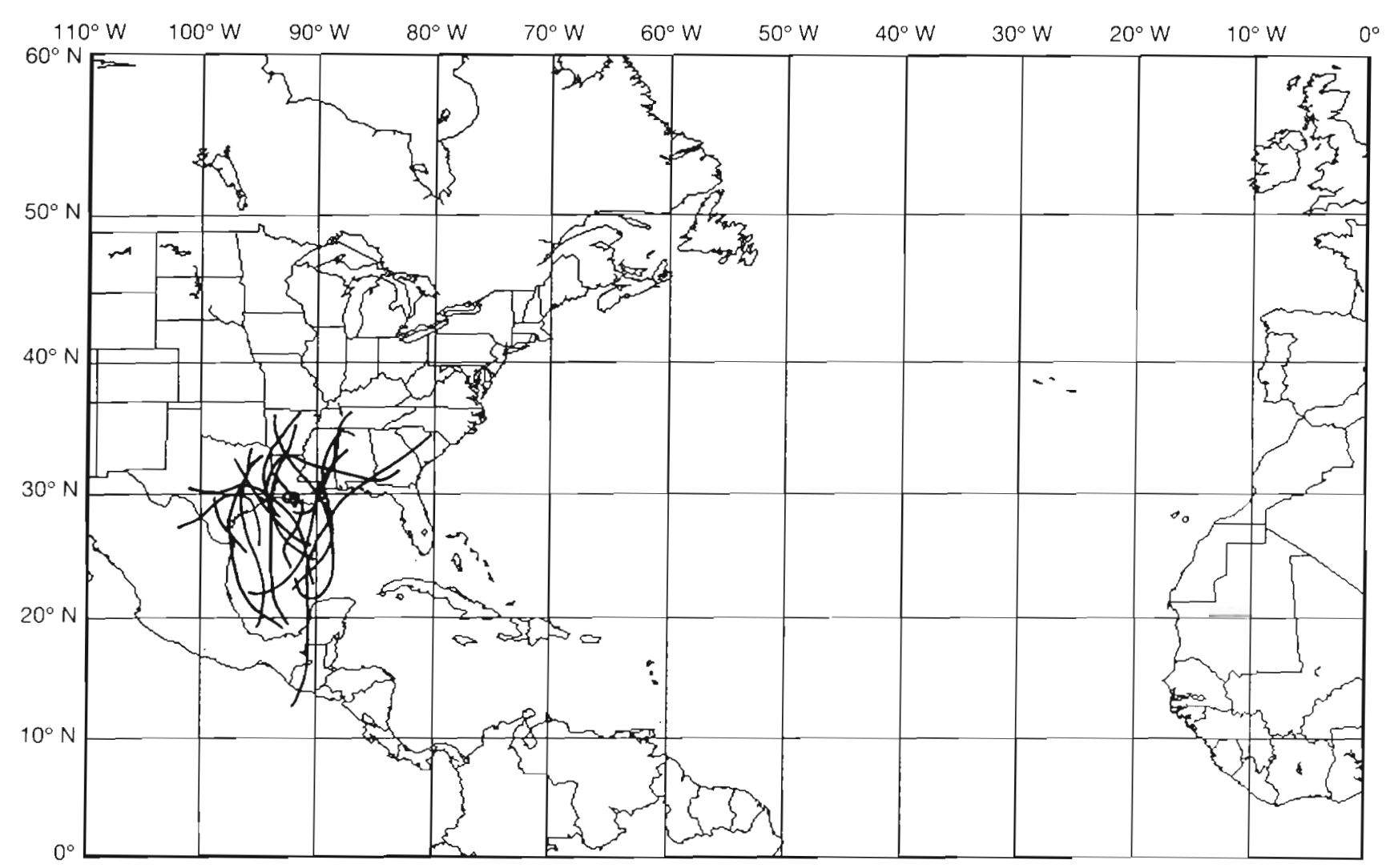

Fig. 3. Paths of tropical cyclones formed in the Western Gulf of Mexico formation region which made landfall along the U.S. coast 


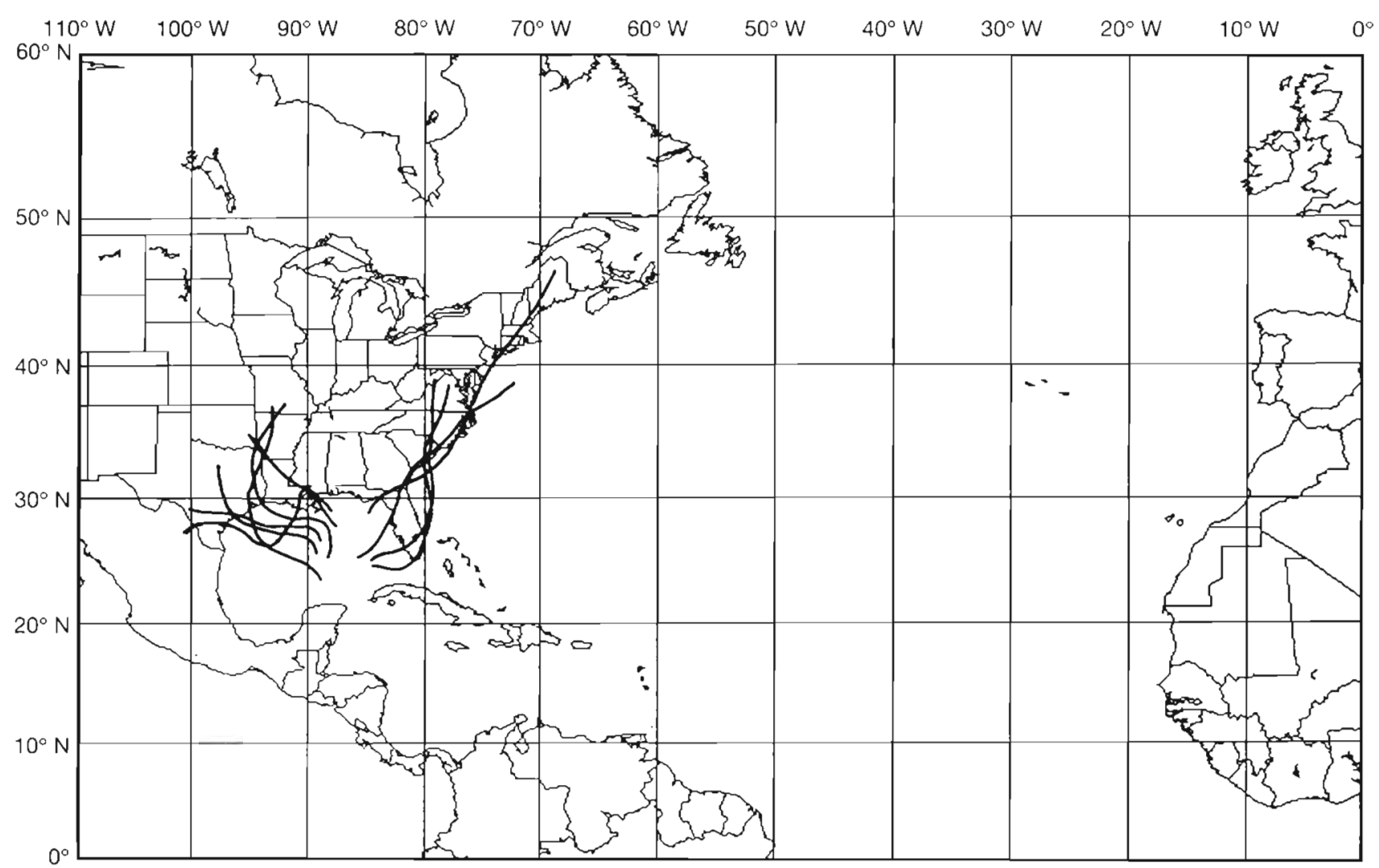

Fig. 4. Paths of tropical cyclones formed in the Eastern Gulf of Mexico formation region which made landfall along the U.S. coast

Table 4. Frequency of tropical cyclones from each formation zone by month (zone abbreviations as in Table 3)

\begin{tabular}{|lcccccc|}
\hline & WG & EG & SWA & CAR & CV & ATL \\
\hline Jun & 2 & 2 & 5 & 0 & 0 & 0 \\
Jul & 3 & 2 & 2 & 0 & 2 & 0 \\
Aug & 2 & 6 & 2 & 7 & 9 & 0 \\
Sep & 4 & 1 & 4 & 11 & 6 & 1 \\
Oct-Nov & 2 & 0 & 5 & 0 & 0 & 1 \\
\hline
\end{tabular}

Tropical cyclones which formed in the Eastern Gulf formation region can be divided into 2 categories, those which tracked to the northeast and those which moved to the northwest (Fig. 4). Interestingly, there were no storms which moved directly north of the formation zone, thereby causing a landfall 'hole' extending roughly from Gulfport, Mississippi, to Apalachicola, Florida. The presence of this non-landfall area may be related to a cold water plume which exists during the early portion of the hurricane season as a result of relatively cold continental waters which drain into the Gulf of Mexico via the Mississippi River. The presence of this plume has been documented through polar orbiter satellite data of sea surface temperatures (D. R.
Smith pers. comm.). This plume may inhibit early season tropical cyclogenesis as well as cyclone movement.

Like the Western Gulf, the Eastern Gulf formation region produced storms which were of low intensity (Table 3). None of the storms which formed attained an intensity higher than Category 1 on the Saffir-Simpson Scale. Again the proximity of the region to the landfall area ultimately played a role, as storms were not able to fully develop before landfall.

The Western Gulf of Mexico formation region produced storms steadily throughout the hurricane season (Table 4) with a slight peak in September. The cyclogenesis in this region is ultimately related to warmwater eddies which spin off the Loop Current and reside in the shallow shelf waters where they may remain for several months (S. A. Hsu pers. cormm.). Many of these eddies spin cyclonically and are typically warmer than the surrounding waters, thereby inducing low level convergence. Cyclogenesis, therefore, is easily induced given proper atmospheric conditions (Lewis \& Hsu 1992).

The Eastern Gulf formation region has a definite peak in cyclogenesis during the month of August (Table 4). Like the Western Gulf, this region produced many early season storms (June and July). This temporal consistency may be due to the fact that the basin 
is relatively shallow (as compared to the Atlantic) and is fed warm water through the Loop Current circulation. Therefore, this basin warms sooner than the deeper Atlantic and is consistently fed low latitude waters which are sufficiently warm for cyclogenesis to occur. This results in the steady production of tropical cyclones throughout the hurricane season with a peak during the time of hottest water temperatures (August).

\section{Southwest Atlantic}

Most of the tropical cyclones which developed in the Southwest Atlantic formation region tracked due north with only slight recurvature toward the northeast poleward of $30^{\circ} \mathrm{N}$ (Fig. 5). A few variations in the mean track occurred as 2 storms initially moved westward toward the Texas coast and 1 storm tracked into open waters only to loop and eventually strike the northeastern U.S. The region produced storms of mainly low intensity but, unlike the previously mentioned regions, some of the storms did achieve higher (up to Category 4) intensity levels (Table 3).

It is interesting that cyclogenesis within this region occurred only during the months of August and
September (Table 4). This is during a time when the STH is usually most developed across the eastern portion of the U.S. This is also the time of highest water temperature. Therefore, when the STH weakens or is displaced toward the east, cyclogenesis may occur over these warm waters. If the STH were strong or displaced westward, shearing of the developing storm would prevail, halting the cyclogenesis process.

\section{Caribbean}

Tropical cyclones which formed within the Caribbean formation region tracked mainly to the northnortheast or to the north-northwest (Fig. 6). Once again a small 'hole' exists through the central Gulf of Mexico where storms did not track. It would seem that the cold water plume would again be responsible for this phenomenon. However, this formation region produced no early season cyclones (Table 4). Therefore, some other mechanism must be responsible for the ultimate storm track. Again, the STH may be responsible as the mean flow or streamlines (Trewartha 1981) either curve around the high at higher latitudes producing southerly flow into the U.S., or drift toward the west constituting the mean easterly flow in the equa-

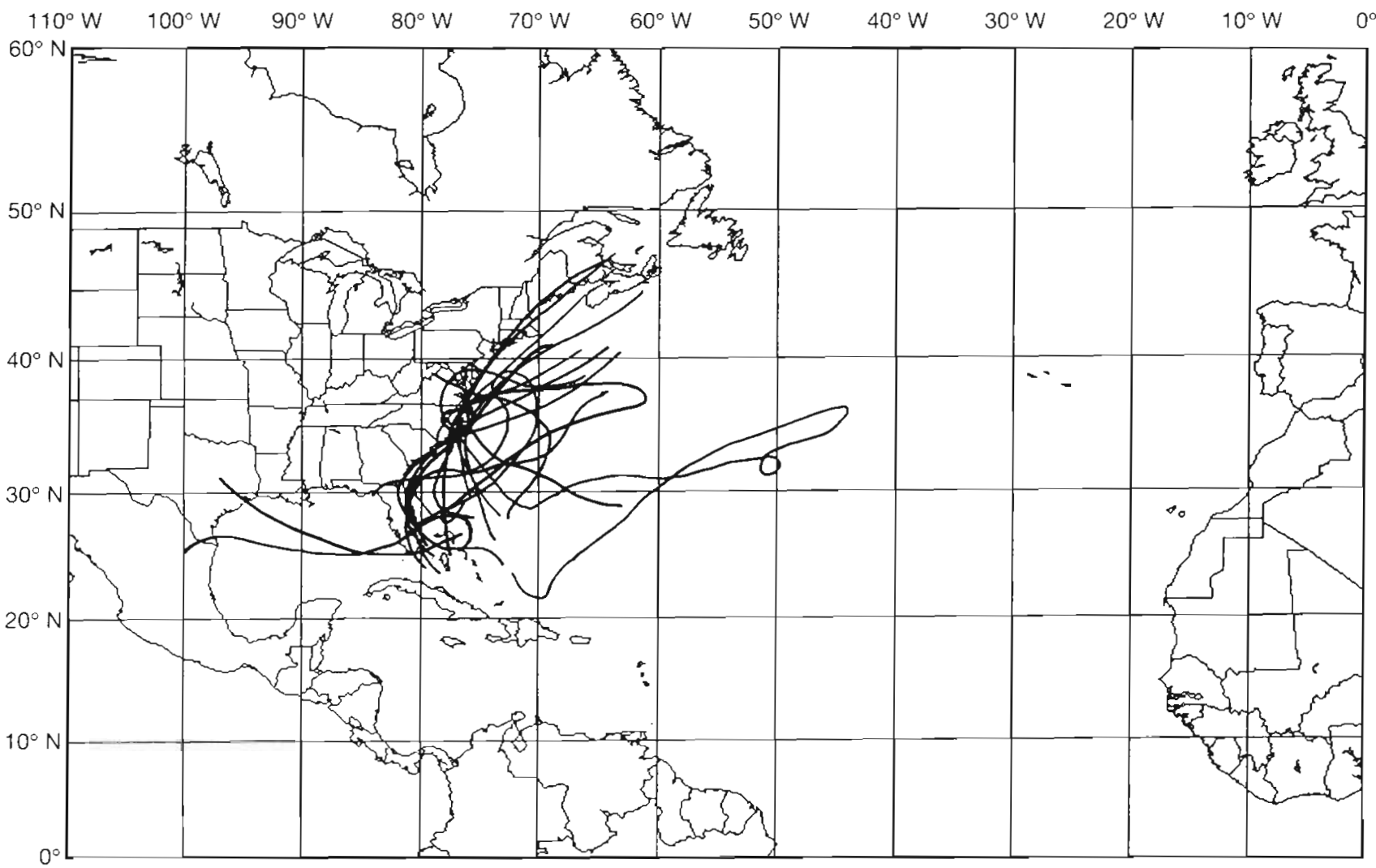

Fig. 5. Paths of tropical cyclones formed in the Southwest Atlantic formation region which made landfall along the U.S. coast 


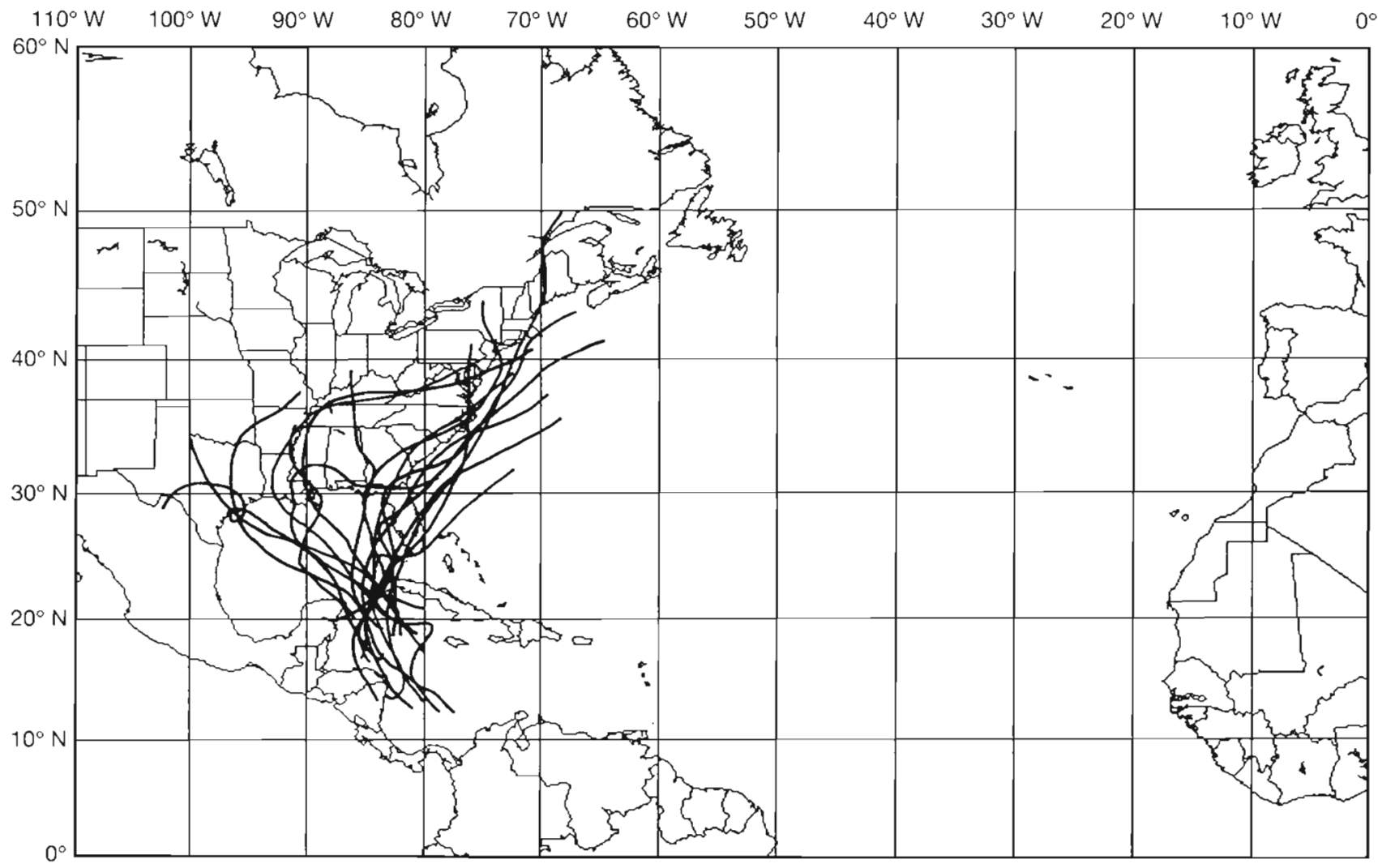

Fig. 6. Paths of tropical cyclones formed in the Caribbean formation region which made landfall along the U.S. coast

torward latitudes. Depending upon the exact cyclogenesis point and the resulting early track, the cyclone may either drift west in the trade winds or move into the southerly flow around the $\mathrm{STH}$, thus accounting for the lack of storms traversing the central Gulf of Mexico.

Storms which developed within this formation region were fairly well distributed in intensity, with low intensity storms dominating (Table 3 ). This is again due to the close proximity between the cyclogenesis area and the point of landfall. The formation region is somewhat distant from the U.S. mainland, therefore allowing a few cyclones to reach a high intensity.

\section{Cape Verde}

Cyclones from the Cape Verde formation region were characterized by the parabolic track most often associated with tropical cyclones (Fig. 7). This track is most representative of the influence of the STH as the storms cannot move into the area dominated by the high due to upper atmospheric shearing. The storms usually skirt this environment and are carried to the west in the mean trade-wind flow. When the influence of the STH diminishes, the storms move into higher latitudes and recurve.
As stated earlier, this formation region produced significantly more intense cyclones than any other region. Although a few of the storms were of low intensity, the majority were Category 4 and 5 storms (Table 3). Of the 17 storms produced within this region, 6 attained the highest category on the Saffir-Simpson Hurricane Intensity Scale - Category 5. Although these storms may not have been of Category 5 intensity at the time of landfall (this study incorporates the highest level of intensity, irrespective of the intensity at landfall), the destructive force of the cyclones was still in place at the time of landfall, causing large amounts of damage. The majority of these Category 5 storms affected the eastern seaboard of the U.S. However, a few (notably Hurricanes Betsy and Gilbert) tracked across the Gulf of Mexico and made landfall along the Gulf Coast.

Cyclogenesis within this formation region was mainly confined to the middle of the hurricane season with a peak during August (Table 4). This is probably due to the relative deepness of the Atlantic Ocean as a whole as well as the prevalence of currents which keep the basin well mixed. The highest water temperatures in the Atlantic exist during August and September after the lag response to increased solar radiation. 


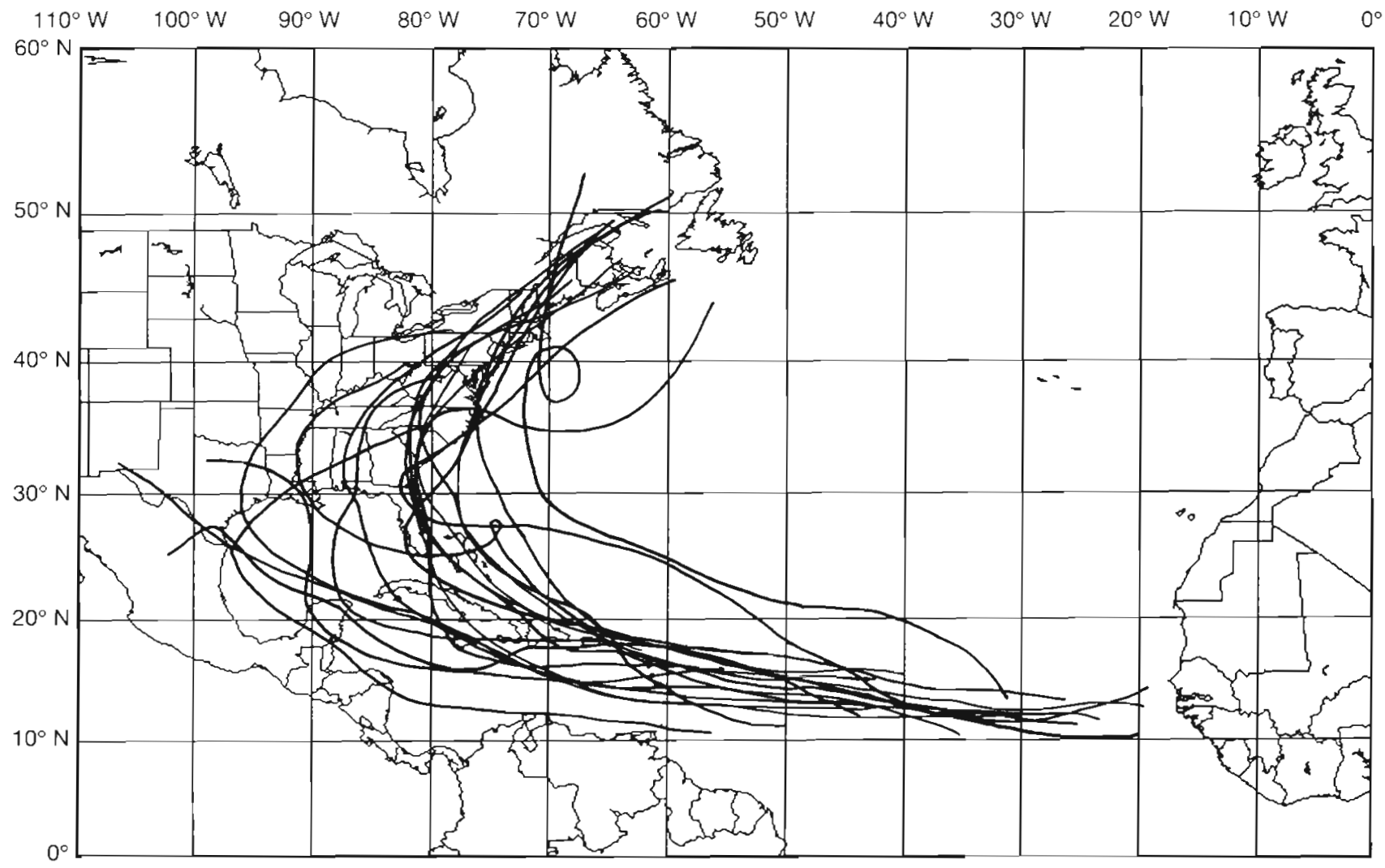

Fig. 7. Paths of tropical cyclones formed in the Cape Verde formation region which made landfall along the U.S. coast

\section{Atlantic}

It is interesting to note that both of the storms which made landfall in the U.S. from the Atlantic formation region had uncharacteristic tracks (Fig. 8). Because of the low number of storms which made landfall in the U.S. as compared to the total number formed, one would assume that a circulation mechanism exists to deter storms from tracking into the U.S. from this region (see Fig. 2). Climatological factors which would inhibit storms from tracking into the U.S. from this formation region are not entirely understood. Both the higher relative latitude of the formation region (inducing early recurvature) and the distance from the mainland may be the primary factors. The STH involvement probably affects both cyclogenesis as well as early recurvature. This may be inferred from the uncharacteristic tracks exhibited by the 2 cyclones which made landfall. A relatively benign circulation must have been present to allow these storms to loop and meander as they did. This would imply that a weak STH was present during both cyclone lifecycles.

Both of these cyclones were of relatively low intensity (Table 3) and both formed during the latter portion of the hurricane season (Table 4). This lends weight to the previous argument in that during the latter months of the hurricane season, the STH begins to contract, producing less of an influence upon the tropical cyclones.

\section{CONCLUSIONS}

This study attempted to identify and discern specific characteristics regarding tropical cyclone formation areas in the North Atlantic basin. Consequently, cyclone paths, points of landfall, intensities and the time of year of occurrence were analyzed in relation to each formation region. It was found that, due to seasonal variations, the formation regions as well as the paths and resulting landfall areas of the tropical cyclones varied. The seasonal variations are responsible for shifts in global circulation regimes which may affect both tropical cyclogenesis and track.

Early and late season cyclones were found to develop over waters which heat earlier during the year (due to depth) and retain the heat longer into the hurricane season (due to mixing with low latitude waters). The Gulf of Mexico and the Caribbean were the primary cyclogenesis regions during these times. 


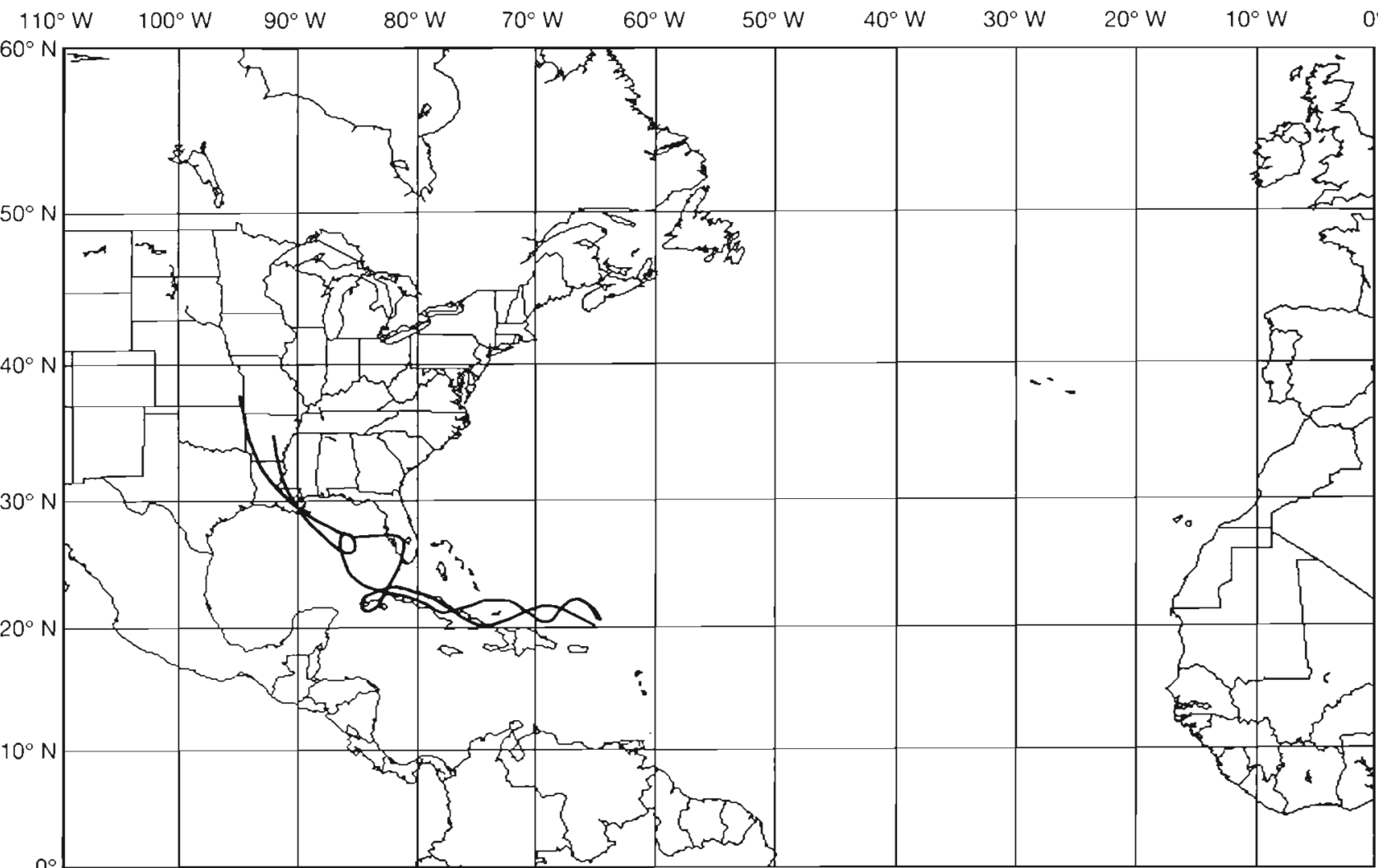

Fig. 8. Paths of tropical cyclones formed in the Atlantic formation region which made landfall along the U.S. coast

Cyclone tracks were found to be either due north or to the northeast out of these genesis areas. This may be related to the strength of the $\mathrm{STH}$, which will either aid early recurvature or help steer storms westward, depending upon the exact location of genesis. The majority of these cyclones were of low intensity which may be related to the proximity of the formation regions to the U.S. This would inhibit the full development of the cyclones before landfall occurred.

Cyclone formation areas shift to the east as the hurricane season matures in response to the warming of ocean waters by a higher solar angle. Due to the large heat capacity of the ocean, peak cyclone frequencies occur a month or two after the highest solar angle. With the eastward shift in cyclogenesis comes an increase in cyclone intensity. This may be related to the location of the formation regions in relation to the U.S. mainland, thus allowing for full storm development before impact. These storms primarily affected the east coast of the U.S. and were not as frequent recently as during the early portions of the climatological record. Again, interaction of the STH was found to be critical with regard to tropical cyclone movement, and variations within this pressure system may be linked to the recent lull in cyclone activity along the eastern seaboard.
The 2 formation regions which produced the most cyclones overall (Cape Verde and Atlantic) did not produce the highest number which made landfall in the U.S. The highest percentage of cyclones making landfall was associated with the Gulf of Mexico regions, due primarily to the close proximity between the formation regions and the U.S. However, the formation region which displayed the most temporal consistency as well as intensity balance was the Southwest Atlantic. Variations in the strength and position of the STH proved crucial to the formation and tracks of cyclones formed within these regions.

Future research should be devoted to further exploration of the relationships between the STH and cyclone movement. A better understanding of these processes may led to a better overall understanding of the process involved in the transport of heat and energy from the tropics into the mid-latitudes. This knowledge may prove increasingly important given current global warming predictions.

Acknowledgements. Thanks to Mr. Phillip Larimore, Cartographic Division, Dept of Geography and Anthropology at LSU, for his drafting of the base maps. 


\section{LITERATURE CITED}

Allen, E. V. (1976). A wind to shake the world Little, Brown and $\mathrm{Co}$., Boston

Case, B. (1988). Atlantic hurricanes - a subdued season. Weatherwise $41(1): 25-29$

Case, B. (1990). Hurricanes, strong storms out of Africa. Weatherwise 43(1): 23-29

Chaston, P. (1988). Hurricanes. National Weather Service Training Center, Kansas City, MO

Crutcher, H. L., Quayle, R. G. (1974). Mariners worldwide guide to tropical storms at sea. Naval Weather Service NAVAIR 50-1C-61, Asheville, NC

Dowdy, S., Wearden, S. (1991). Statistics for research. John Wiley \& Sons, New York

Eagleman, J. (1983). Severe and unusual weather. Trimedia Publishing Co., Lenexa, KS

Elsberry, R. L. (1985). Tropical cyclone motion. In: Elsberry, R., Frank, W., Holland, G., Jarrell, J., Southern, R. (eds.) A global view of tropical cyclones. Office of Naval Research Marine Meteorology Program, Monterey, p. 91-128

Frank, W. M. (1985). Tropical cyclone formation. In: Elsberry, R., Frank, W., Holland, G., Jarrell, J., Southern, R. (eds.) A global view of tropical cyclones. Office of Naval Research Marine Meteorology Program, Monterey, p. 53-87

Gray, W. M. (1968). Global view of the origin of tropical disturbances and storms. Mon. Weather Rev. 105: $1171-1188$

Gray, W. M. (1990). Strong ssociation between West African rainfall and U. S. landfall of intense hurricanes. Science 249: 1251-1256

Hebert, P. J., Poteat, K. O. (1975). A satellite classification technique for subtropical cyclones. NOAA Technical Memorandum, NWS SR-83, Fort Worth, TX

Hsu, S. A. (1988). Coastal meteorology. Academic Press, San Diego

Jarrell, J. D. (1985). Impact of tropical cyclones. In: Elsberry, R., Frank, W., Holland, G., Jarrell, J., Southern, R. (eds.) A global view of tropical cyclones. Office of Naval Research
Marine Meteorology Program, Monterey, p. 133-145

Landsberg, H. E. (1960). Do tropical storms play a role in the water balance of the Northern Hemisphere? J. geophys. Res. 65(4): 1305-1307

Lawrence, M. B. (1989). Return of the hurricanes. Weatherwise 42(1): 22-27

Lewis, J. K., Hsu, S. A. (1992). Mesoscale air-sea interactions related to tropical and extratropical storms in the Gulf of Mexico. J. geophys. Res. 97(C2): 2215-2228

Neumann, C., Jarvinen, B., Pike, A. (1987). Tropical cyclones of the North Atlantic Ocean, 1871-1986. National Climatic Data Center, Asheville, NC

Reading, A. J. (1989). Caribbean tropical storm activity over the past four centuries. Int. J. Climatol. 10: 365-376

Shapiro, M. (1989). NOAA's Environmental Research Laboratories, Boulder, CO. Bull. Am. Meteorol. Soc. 70(11) $1468-1469$

Simpson, R. H., Riehl, H. (1981). The hurricane and its impact Louisiana State University Press, Baton Rouge

Southern, R. L. (1979). The global socio-economic impact of tropical cyclones in the Philippines. Aust. Meteorol. Mag. 7: $175-195$

Spencer, T., Douglas, I. (1985). The significance of environmental change: diversity, disturbance and tropical ecosystems. Environmental change and tropical geomorphology. Allen and Unwin, London

Trewartha, G. T. (1981). The earth's problem climates, 2nd edn. University of Wisconsin Press, Madison

Vallee, D. R. (1990). Variations in tropical cyclone characteristics during ENSO events. Eastern Region Technical Attachment, National Weather Series, No. 90-8D, September. NOAA, Washington, DC

Vega, A. J. (1993). Variations in tropical cyclone landfall along the Gulf and Atlantic Coast, 1930-1989. GeoJournal (in press)

Walsh, R. P. D. (1977). Changes in the tracks and frequency of tropical cyclones in the Lesser Antilles from 1650 to 1975 and some geomorphological and ecological implications. Swansea Geogr. 15: 4-11

Manuscript first received: January 22, 1993

Revised version accepted: June 25, 1993 